\title{
Analysis of In-Pipe Inspection Robot Structure Design
}

\author{
Meng $\operatorname{Han}^{1, \mathrm{a}}$, Jun Zhou ${ }^{1, \mathrm{~b}^{\star}}$, Xun Chen ${ }^{1, \mathrm{c}}$, Lihong $\mathrm{Li}^{1, \mathrm{~d}}$ \\ ${ }^{1}$ School of Mechanical Engineering, Shandong University, Jinan 250061, China \\ ahanmeng2235@126.com, bsunger2010@qq.com, 'zhoujunpl@qq.com, dihong@qq.com
}

Keyword: in-pipe inspection robots, single locomotion, multiple locomotion

\begin{abstract}
In the past 20 years, numerous in-pipe inspection robots (IPIRs) have been designed and utilized. According to the propulsion mechanism amount, these in-pipe inspection robots (IPIRs) can be summarized into two categories, i.e. single locomotion system and multiple locomotion system. This paper presents the classic structure features and characters of the two categories of IPIRs, and furthermore compares their own advantages and limitations, as well as performances of each type IPIR. Ultimately, it is concluded that the multiple locomotion type In-pipe inspection robot has become increasingly current developing trend.
\end{abstract}

\section{Introduction}

Recently, the utilization of in-pipe inspection robot has grown increasingly popular in engineering fields including nuclear power plant industry, sewage system, and petroleum industry etc. With carrying various sensors, these in-pipe inspection robots (IPIRs), walking along the pipeline inside, are applied to inspect defects, cracks and erosion caused by strain ageing, creep deformation, water erosion, etc.

During the latest 20 years, numerous in-pipe inspection robots (IPIRs) have been designed and fabricated based on several elementary forms according to the locomotion patterns. They can be classified into wheel-type, caterpillar-type, snake-type, legged type, inchworm-type, screw-type and PIG-type [1]. Each type of in-pipe inspection robot (IPIR) is built in order to satisfy distinct design requirements for specific environment, while the other types might not be appropriate for the special occasion. Furthermore, these in-pipe inspection robots (IPIRs) can also be summarized into two categories on the basis of the propulsion mechanism amount, namely single locomotion system and multiple locomotion system.

\section{Single Locomotion}

Single locomotion means that in-pipe inspection robots (IPIRs) have single propulsion mechanism, which also can be classified into wheeled type, caterpillar type, snake type, legged type, inchworm type, and PIG type. Each type of the locomotion exhibits its own special characteristic depending on in-pipe on-line circumstances.

Wheel-type with single locomotion [2] has so simple structure that its wheels are directly connected to motor to get desired locomotion, as shown in Fig.1.(a) Meanwhile, it is capable of steering in different directions with using its differential drive system. Furthermore, it has the capacity of traversing sharp intersections with the sufficiently designed clearance space between the front and rear wheels. However, compared to the wheel wall-pressed robot with multiple locomotion, it has the poorer velocity control, inferior adaptability as well as worse required frictional force to move up the vertical pipe. 


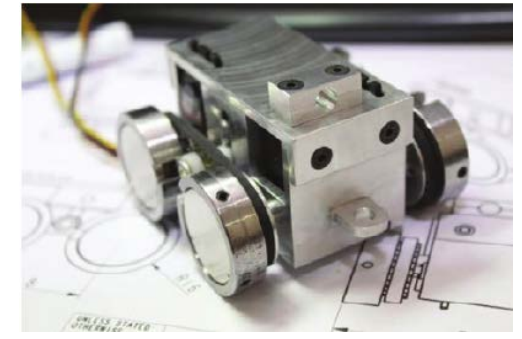

(a)

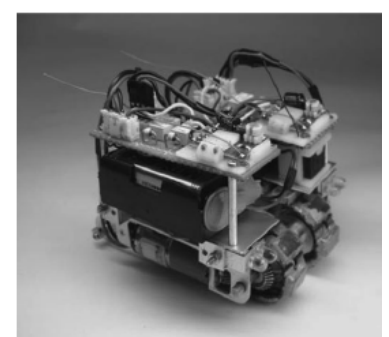

(b)

Fig. 1: (a) Wheel-type robot prototype [2], (b) Caterpillar-type robot prototype [3]

Caterpillar-type robot with single locomotion has also simple structure [3], with the belt bounding wheels in order to exert more friction for the robot, thus making it able to move on uneven surface, as shown in Fig.1.(b). Nevertheless, this caterpillar-type robot has no ability to climb vertical and inclined pipe lines.

PIG-type, namely the pipe inspection gauges (PIG) type [4], is not equipped with any driving mechanism; Instead, it is driven with the help of the force from the fluid differential pressure between top and bottom faces inside liquid-filled pipes. Accordingly, this type of passive robot does not consume energy when performing tasks. However, the movement pattern is considerably limited.

Snake-type, also named serpentine robot as schematically illustrated by Fig. 2.(a) [5], consists of several identical body segments. Each joint is driven by a pair of antagonistic muscles, i.e., flexor and extensor, within a pre-specified range of rotation. This serpentine robot moves forward with the propulsive force from the low friction along the longitudinal direction as well as the high friction along the latitudinal direction.

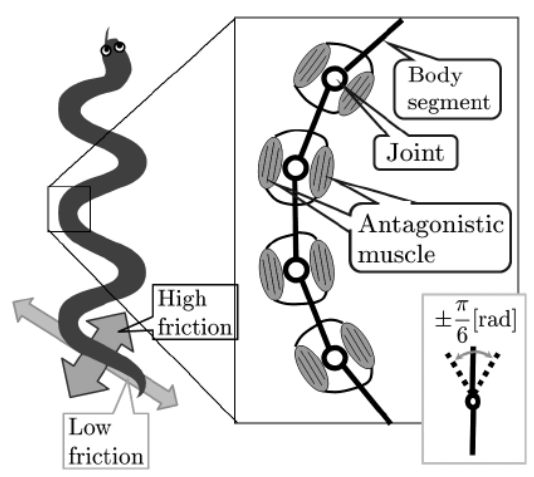

(a)

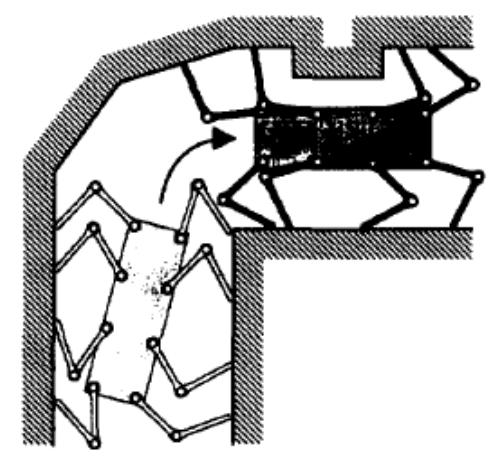

(b)

Fig. 2: (a) Structure of serpentine robot [5], (b) Simulation of legged pipe robot [6]

Legged type is a kind robot with legs, which are pushed against the pipe walls to support the body (see Fig. 2.(b)) [6]. Those implemented legs make the robot have the ability to step over almost all surface shapes, and enable the robot to move in extremely complex shaped hollows. On the other hand, the disadvantage of a robot with legs is that it needs more motors and consumes more energy to drive the robot, and meanwhile, the whole control task is much more complicate.

Inchworm-type robot is generally equipped with moving mechanisms, and it makes full use of friction by using as large area as possible between the robot and inner pipe wall. Generally, the moving mechanisms applied in these robots are usually elastic legs or air chambers [7];

\section{Multiple Locomotion}

As shown in Fig.1 to Fig.4 above, each of the locomotion exhibits their own advantages and disadvantages on in-pipe working condition. In order to overcome the limitation of each single propulsion mechanism, it is extremely necessary to assimilate two or more locomotion system as new innovative drive system, namely multiple locomotion drive system. The multiple locomotion 
system is considered to conclude three patterns, i.e., caterpillar wall-pressed type, wheeled wall-pressed type, and wheeled wall pressing screw type.

Caterpillar wall-pressed type generally combines caterpillar system and wall-pressed system to allow the robot to adapt complex pipe condition, such as diameter-change pipeline, uneven surface, curvature as well as T-branch. As shown in Fig.3, the type often consists of three main structures, i.e., caterpillar wheel as caterpillar system to provide good traction force to move forward and backward, flexible linkage mechanism as wall-pressed system to press the robot against the wall, and main body [8].
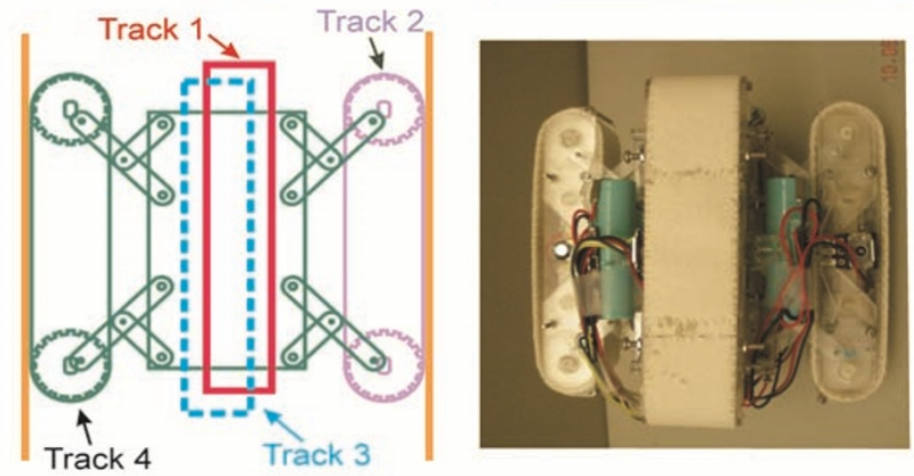

Fig. 3 Caterpillar wall-pressed structure [8]

Wheeled wall-pressed type integrates the wheeled type with differential drive system in a wall press robot so as to enhance the performance for the speed mobility. Compared to the legged type, this type can satisfy specific design requirements with more simple structure. As shown in Fig.4.(a), the wheeled wall-pressed robot is composed of main body, wheel mechanism with good steering ability, and flexible linkage mechanism [9].

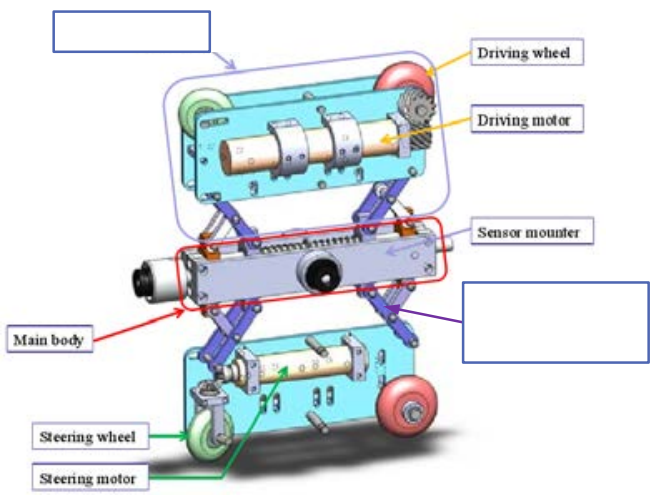

(a)

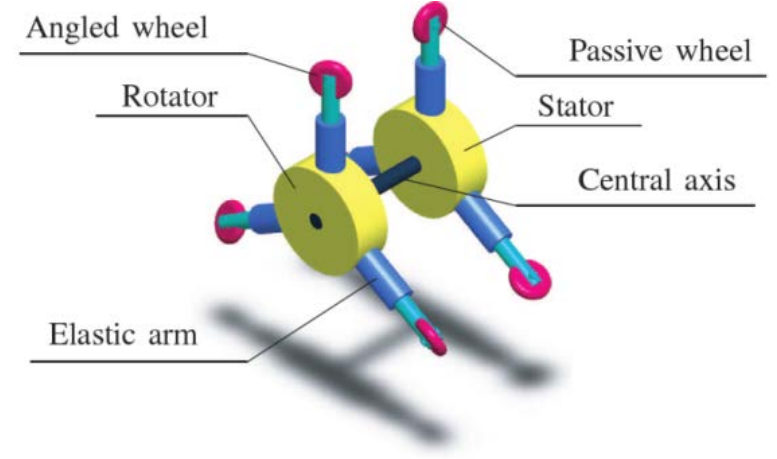

(b)

Fig. 4: (a) Wheeled wall-pressed [9], (b) Wheeled wall pressing screw structure [10]

Wheeled wall pressing screw type assimilates three locomotion systems, i.e., wheel system and wall press system providing the stability to the robot, as well as screw type motion. Screw type motion consists of the rotator converting the rotation of motor into translation of robot, and the stator preventing the robot from reaction force, as shown in Fig.4.(b)

\section{Discussion}

In view of the description of in-pipe inspection robot above, each of single locomotion system offers few advantages as well as certain limitation under special working condition adaptability. Wheeled type, especially with differential driving, is widely used on account of its ability in branches navigation. Caterpillar type can adapt to travelling on uneven surface and crossing obstacles in the pipe. Snake and legged type have their own significance in high mobility and branches pipes. Inchworm type robots have an advantage of moving in curved pipes. Compared to the single locomotion, the hybrid locomotion can overcome the limitation of each single propulsion mechanism. The advantages and disadvantages of the single and hybrid locomotion in-pipe robot 
are summarized in Table 1. The detailed comparison performance for each type of robots discussed earlier is shown in Table 2.

\section{Conclusion}

Based on the literature reviewed, it is concluded that compared to other mechanisms, multiply locomotion type In-pipe inspection robotic mechanism has more advantages. Due to the single locomotion's limitation under special working condition adaptability, the multiply locomotion type In-pipe inspection robotic has become increasingly current developing trend, albeit suffering from certain limitations, such as no adapting the pipe with sudden change diameter with branches.

Table 1 Comparison of characteristics on IPIR

\begin{tabular}{|c|c|c|c|}
\hline & Type & Advantages & Disadvantages \\
\hline \multirow{6}{*}{$\begin{array}{l}\text { Single } \\
\text { locomotion }\end{array}$} & Wheel-type & $\begin{array}{l}\text { Simple in structure } \\
\text { Able to steer }\end{array}$ & $\begin{array}{l}\text { No ability to climb } \\
\text { Poorer velocity control }\end{array}$ \\
\hline & Caterpillar-type & Able to cross obstacle. & $\begin{array}{l}\text { No ability to climb } \\
\text { Bigger in size }\end{array}$ \\
\hline & Snake-type & $\begin{array}{l}\text { Able to climb } \\
\text { Can adapt various pipe } \\
\text { diameters }\end{array}$ & $\begin{array}{l}\text { Complex in structure. } \\
\text { Difficult to control }\end{array}$ \\
\hline & Legged type & $\begin{array}{l}\text { Able to climb } \\
\text { Can adapt various pipe } \\
\text { diameters }\end{array}$ & $\begin{array}{l}\text { Complex in structure. } \\
\text { need more actuator }\end{array}$ \\
\hline & Inchworm-type & Simple in structure & Lower speed mobility \\
\hline & PIG-type & No need for actuator & $\begin{array}{l}\text { Difficult to control speed } \\
\text { Poorer adapting in pipe } \\
\text { shape }\end{array}$ \\
\hline \multirow{3}{*}{$\begin{array}{l}\text { Multiple } \\
\text { locomotion }\end{array}$} & $\begin{array}{l}\text { Caterpillar } \\
\text { wall-pressed type }\end{array}$ & $\begin{array}{l}\text { Can adapt various pipe } \\
\text { diameters. } \\
\text { High traction force. } \\
\text { Omni-directional } \\
\text { motion. } \\
\text { Able to cross obstacle. }\end{array}$ & $\begin{array}{l}\text { High friction force. } \\
\text { Bigger in size. }\end{array}$ \\
\hline & $\begin{array}{l}\text { Wheeled } \\
\text { wall-pressed type }\end{array}$ & $\begin{array}{l}\text { Less friction force. } \\
\text { Omni-directional } \\
\text { motion. } \\
\text { Able to climb. }\end{array}$ & $\begin{array}{l}\text { Less efficient on uneven } \\
\text { surface. } \\
\text { Require bigger radius of } \\
\text { curvature to turn. }\end{array}$ \\
\hline & $\begin{array}{l}\text { Wheeled wall } \\
\text { pressing screw type }\end{array}$ & $\begin{array}{l}\text { Require small radius } \\
\text { of curvature to turn. } \\
\text { Smaller in size. } \\
\text { Able to climb. }\end{array}$ & $\begin{array}{l}\text { Less efficient on uneven } \\
\text { surface } \\
\text { No omni-directional motion }\end{array}$ \\
\hline
\end{tabular}

Table 2: (a) Performance table on Single locomotion

\begin{tabular}{llcccccc}
\hline Performances & Wheel & Caterpillar & Snake & Legged & Inchworm & PIG \\
\hline Steerability & $\sqrt{\sqrt{ }}$ & $\sqrt{ }$ & $\sqrt{ }$ & $\sqrt{ } \sqrt{ }$ & $\sqrt{ }$ & $\times$ \\
\hline Variable pipe diameter & $\sqrt{ }$ & $\sqrt{ }$ & $\sqrt{ }$ & $\sqrt{ }$ & $\sqrt{ }$ & $\times$ \\
\hline High speed mobility & $\sqrt{ } \sqrt{ }$ & $\sqrt{ }$ & $\sqrt{ }$ & $\sqrt{ }$ & $\times$ & $\times$ \\
\hline \multirow{3}{*}{$\begin{array}{c}\text { Pipe shape } \\
\text { adapting }\end{array}$} & Level & $\sqrt{ } \sqrt{ }$ & $\sqrt{ } \sqrt{ }$ & $\sqrt{ } \sqrt{ }$ & $\sqrt{ } \sqrt{ }$ & $\sqrt{ } \sqrt{ }$ & $\sqrt{ } \sqrt{ }$ \\
\cline { 2 - 8 } & Vertical & $\times$ & $\times$ & $\sqrt{ }$ & $\sqrt{ } \sqrt{ }$ & $\sqrt{ }$ & $\times$ \\
\cline { 2 - 8 } & T- joint & $\sqrt{ }$ & $\sqrt{ }$ & $\sqrt{ }$ & $\sqrt{ }$ & $\times$ & $\times$ \\
\cline { 2 - 8 } & L- joint & $\times$ & $\times$ & $\sqrt{ }$ & $\sqrt{ }$ & $\times$ & $\times$ \\
\hline \multirow{2}{*}{$\begin{array}{l}\text { Structure of } \\
\text { robot }\end{array}$} & Simple & $\sqrt{ } \sqrt{ }$ & $\sqrt{ }$ & $\sqrt{ }$ & $\times$ & $\sqrt{ }$ & $\sqrt{ }$ \\
\cline { 2 - 8 } & Stable & $\times$ & $\sqrt{ }$ & $\sqrt{ }$ & $\sqrt{ }$ & $\sqrt{ }$ & $\sqrt{ }$ \\
\hline
\end{tabular}


Table 2: (b) Performance table on Multiple locomotion

\begin{tabular}{|c|c|c|c|c|}
\hline \multicolumn{2}{|c|}{ Performances } & $\begin{array}{c}\text { Caterpillar } \\
\text { wall-pressed }\end{array}$ & $\begin{array}{c}\text { Wheeled } \\
\text { wall-pressed }\end{array}$ & $\begin{array}{c}\text { Wheeled wall-pressed } \\
\text { screw }\end{array}$ \\
\hline \multicolumn{2}{|l|}{ Steerability } & $\sqrt{ }$ & $\sqrt{ }$ & $\sqrt{ }$ \\
\hline \multicolumn{2}{|c|}{ Variable pipe diameter } & $\sqrt{\sqrt{ }}$ & $\sqrt{\sqrt{ }}$ & $\sqrt{\sqrt{ }}$ \\
\hline \multicolumn{2}{|c|}{ High speed mobility } & $\sqrt{ } \sqrt{ }$ & $\sqrt{\sqrt{ }}$ & $\times$ \\
\hline \multirow{4}{*}{$\begin{array}{l}\text { Pipe shape } \\
\text { adapting }\end{array}$} & Level & $\sqrt{\sqrt{ }}$ & $\sqrt{\sqrt{ }}$ & $\sqrt{\sqrt{ } \sqrt{ }}$ \\
\hline & Vertical & $\sqrt{\sqrt{ }}$ & $\sqrt{\sqrt{ }}$ & $\sqrt{\sqrt{ } \sqrt{ }}$ \\
\hline & T- joint & $\sqrt{\sqrt{ }}$ & $\sqrt{\sqrt{ }}$ & $x$ \\
\hline & L- joint & $\sqrt{\sqrt{ }}$ & $\sqrt{\sqrt{ } \sqrt{ }}$ & $\sqrt{\sqrt{ }}$ \\
\hline \multirow{2}{*}{$\begin{array}{l}\text { Structure of } \\
\text { robot }\end{array}$} & Simple & $\sqrt{ }$ & $\sqrt{ } \sqrt{ }$ & $\sqrt{ } \sqrt{ }$ \\
\hline & Stable & $\sqrt{\sqrt{ }}$ & $\sqrt{ }$ & $\sqrt{\sqrt{ }}$ \\
\hline
\end{tabular}

Indicator: $\quad \times$ Poor $\sqrt{ }$ Fair $\sqrt{ } \sqrt{ }$ Good $\quad \sqrt{ } \sqrt{ }$ Excellent

\section{Acknowledgements}

The authors wish to thank National Natural Science Foundation of China (Grant No.51375268) and Independent Innovation Foundation of Shandong University (Grant No.2012ZD009).

\section{References}

[1] M. M. Moghaddam and A. Hadi. Control and guidance of a pipe inspection-PIC. In Proc. Int. Symp. Automations, Robotics, 2005, pp. 11-14.

[2] Md Raziq Asyraf Md Zin, Khairul Salleh Mohamed Sahari, Juniza Md Saad, Adzly Anuar, and Abd Talip Zulkarnain. Development of a Low Cost Small Sized In-Pipe RobotInternational Synposimn on Robotics and Intelligent Sensors, 2012 (IRIS 2012), pp. 1469-1475.

[3] Kosuke Nagaya, Tornohiko Yoshino, Makoto Katayarna, Iwanori Murakarni, and Yoshinori Ando. Wireless Piping Inspection Vehicle Using Magnetic Adsorption Force. IEEE/ASME TRANSACTIONS ON MECHATRONICS, VOL. 17, NO.3, JUNE 2012, pp. 474-479.

[4] J. Okamoto Jr, J. C. Adamowski, M. S. G. Tsuzuki, F. Buiochi and C. S. Camerini. Autonomous system for oil pipelines inspection, Mechatronics, 1999, 9: 731-743.

[5] Wataru Watanabe, Toshihiro Kawakatsu, Akio Ishiguro. Rapid and Cheap Learning by Exploiting Biarticular Muscles-A Case Study with a Two-Dimensional Serpentine Robot. Advanced Robotics, 2008, 22: 1683-1696.

[6] W. Neubauer, A spider-like robot that climbs vertically in ducts or pipes, Proc. IEEE/RSJ International Conference on Intelligent Robotics and Systems, 1994, pp.1178-1185.

[7] Jinwei Qiao, Jianzhong Shang, and Andrew Goldenberg. Development of Inchworm In-Pipe Robot Based on Self-Locking Mechanism, IEEE/ASME Transactions On Mechatronics, Vol. 18, No. 2, April 2013 799, pp. 799-806.

[8] Jong-Hoon Kim, Gokarna Sharma, and S. Sitharama Iyengar. FAMPER: A Fully Autonomous Mobile Robot for Pipeline Exploration, IEEE, 2010, pp. 517-523.

[9] Young-Sik Kwon, Bae Lee, In-Cheol Whang, Whee-kuk Kim and Byung-Ju Yi. A Flat Pipeline Inspection Robot with Two Wheel Chains, IEEE International Conference on Robotics and Automation, 2011, pp. 5141-5146.

[10] Atushi Kakogawa, Shugen Ma. Mobility of an In-pipe Robot with Screw Drive Mechanism inside Curved Pipes, IEEE Int. Conference of Robotics and Bimimetics, 2010, pp. 1530-1535. 